\title{
Data quality in the Norwegian dairy herd recording system: Agreement between the national database and disease recording on farm
}

\author{
M. N. Espetvedt, ${ }^{* 1}$ O. Reksen, ${ }^{*}$ S. Rintakoski, $†$ and 0. Østerås ${ }^{*} \ddagger$ \\ *Norwegian School of Veterinary Science, Department of Production Animal Clinical Sciences, PO Box 8146 Dep., NO-0033 Oslo, Norway \\ †University of Helsinki, Department of Veterinary Biosciences, PO Box 66, FI-00014 Helsinki, Finland \\ ‡TINE Extension Services, TINE SA, PO Box 58, 1431 Ås, Norway
}

\section{ABSTRACT}

The majority of herds in Norway participate in the national dairy herd recording system. For disease events, this involves transferring information registered on farm, using individual cow health cards (CHC), to the central cattle database (CCD). Before using data from such a database, validation with an aim of describing data quality should be performed, but is rarely done. In this study, diagnostic events from $\mathrm{CHC}$ and CCD from 74 dairy herds were compared. Events in 2008 from female cattle with minimum age of $1 \mathrm{yr}$ were included $(\mathrm{n}=1,738)$. Discrepancies between the 2 data sources and assessment of data quality were evaluated using agreement between events on CHC and in CCD, calculating completeness and correctness for the CCD, and using a multivariable regression model for agreement $(1 / 0)$. The agreement evaluation described the concordance between the 2 data sources, whereas the calculations of completeness and correctness depended on a reference data source assumed to be more reliable. Completeness of the CCD was defined as the proportion of diagnostic events on the CHC that was recorded therein. Correctness was defined as the proportion of the CCD events that was also recorded on the CHC, and with the same date and diagnostic code. The agreement was up to $87.5 \%$, the majority of disagreement being caused by unreported events on the $\mathrm{CHC}$ (between 10 and $12 \%$ of all events). Completeness of the CCD was regarded as high, between 0.87 and 0.88 , and correctness excellent, between 0.97 and 0.98. The multivariable regression model found 4 factors that increased the odds for diagnostic events being in agreement between CHC and CCD. These were the events occurring during the 305-d lactation period; the herd size being 75 cows or less; the event occurring during the spring, summer, or winter rather than autumn; and lastly, the diagnostic code for the disease event being

Received September 10, 2012.

Accepted January 2, 2013.

${ }^{1}$ Corresponding author: mari.espetvedt@nvh.no preprinted on the $\mathrm{CHC}$, involving a simple check mark as opposed to writing a 3-digit code. The model found a high degree of clustering within herd. In conclusion, disease data in the Norwegian national database for dairy cows are valid to use for epidemiologic research, having in particular an excellent correctness, but it is of concern that at least $10 \%$ of data are missing. The proportion of unreported data should be taken into consideration whenever data from this database are used. Reasons for discrepancies found are important to be aware of in any work aiming to improve data transfer from farm to central databases.

Key words: database validation, completeness and correctness, data transfer, dairy cow

\section{INTRODUCTION}

Several countries have established production animal recording systems (International Committee for Animal Recording, 2012). Dairy cattle recording systems have become an essential part of intensive dairy farming today, recording varying amounts of production and health data, on both the individual and herd level. Electronic recording may occur purely on farm in own herd information management systems; for example, InterHerd (http://www.interagri.org/E/IH/interherd. htm) in several European countries (NMR, 2010); DairyCOMP 305 (http://www.vas.com/dairycomp. jsp), PCDART (http://www.dairyone.com/FarmServices/PCDart/default.htm), and DHI-Plus (http:// www.dhiprovo.com/solutions/dhiplus.asp) in the United States (Wenz and Giebel, 2012); and DairyWIN (http://www.dairywin.co.nz/) developed in New Zealand (EpiCentre, 2005). Alternatively, recording is in central databases on regional or even national levels as in the Nordic countries (Olsson et al., 2001), The Royal Dutch Cattle Syndicate (NRS, 1993), the Australian Dairy Herd Improvement Scheme, and the National DHIA in the United States (ADHIS, 2012; National DHIA, 2012). The recording of production, reproduction, and health data can be of great benefit to the farmer, guiding daily decisions and aids in the detec- 
tion of change in health and productivity over time (for example, the emergence of a subclinical mastitis problem). The added advantage with centralized systems is that they can provide comparison among herds and are accessible, useful data sources for epidemiologic research (Bartlett et al., 1986) and breeding programs (Heringstad et al., 2004).

The Norwegian Dairy Herd Recording System (NDHRS) is a centralized nationwide system that has included the option of disease recording since 1975. In 2011, $98.3 \%$ of Norwegian dairy herds, a total of 8,935 herds, participated with disease recording [TINE SA (The Norwegian Dairy Association), Ås, Norway; TINE Rådgiving, 2012]. The NDHRS records production parameters such as milk yield and composition, carcass quality at slaughter, and calving and reproductive information, together with disease and treatment data. Recording of disease data on farm is mandatory, but participation in the NDHRS with transfer of disease data to the central database is voluntary. Historically, the high participation in the NDHRS is related to the long standing cooperative organization of dairy farming, the national dairy cooperative starting in the late 1800s. Today, usefulness of access to several types of data from the system is well recognized by herd managers and veterinarians. Since 1996, health reports have been sent periodically to participating dairy herds. In 2005, Internet-based information systems for health data, including disease events, reproductive events, and milk sample results became available for the farmer and selected herd health advisors (Østerås et al., 2007). Descriptions of variables in the central database are available at http://www.kkvet.no (NDHRS, 2012). Numerous examples of published research fully or partly based on data available in this cattle health database can be found (Hardeng and Edge, 2001; Sogstad et al., 2006; Whist and Østerås, 2007; Garmo et al., 2008; Andersen et al., 2012). Despite extensive use of data in the NDHRS for several years, only recently has validation work describing data quality of recorded disease events in cows been carried out. This was in a comparative validation study of the Danish, Finnish, Norwegian, and Swedish recoding systems (Espetvedt et al., 2012; Lind et al., 2012; Wolff et al., 2012). Before this, only calf health data were validated in Norway (Gulliksen et al., 2009). The study with the 4 Nordic countries was concerned with finding the proportion of farmer-observed clinical disease events that was recorded in national databases for specific diseases, but did not separate out data loss only occurring during the transfer from written records on farm to the central database. Examples of other animal disease database validation studies outside of Norway are limited, and the majority can be found in other Nordic countries: some for cattle (Bartlett et al., 2001; Mörk et al., 2009, 2010; Rintakoski et al., 2012), horses (Penell et al., 2007, 2009), and dogs and cats (Egenvall et al., 1998; Nødtvedt et al., 2006) Whereas Pollari et al. (1996) studied data quality for a small animal hospital database at the Ontario Veterinary College, Mulder et al. (1994) assessed the quality and usefulness for research of practice-generated computerized medical records for dairy cows in Canada, and Salman et al. (1988) validated disease diagnoses reported to the National Animal Health Monitoring System for a Colorado beef feedlot.

Investigating and describing data quality in animal disease databases have been carried out in different ways and using varying terminology, including evaluating agreement between 2 data sources for a dog and cat insurance database (Egenvall et al., 1998), describing completeness and correctness for the Swedish and Finnish cattle databases (Mörk et al., 2010; Rintakoski et al., 2012), and calculating sensitivity and positive predictive value (comparable to completeness and correctness, respectively) for an equine insurance database (Penell et al., 2007). Furthermore, in Sweden, the investigation of the spatial relationship between recorded mastitis incidence and SCC (Wolff et al., 2011), and investigation of risk factors for data loss in the Finnish system using logistic regression (Rintakoski et al., 2012) have been done. Specific guidelines do not exist for such work, but certain frameworks have been suggested within the context of human databases, where more validation work has been carried out (Sørensen et al., 1996; Hogan and Wagner, 1997; Arts et al., 2002). However, the most appropriate way may vary according to the design of the registration system and the aim of the validation work (Abate et al., 1998). In a systematic review of papers assessing electronic human patient records, it was concluded that there were a lack of standardized methods for assessment of quality of data and that this made it difficult to compare results between studies (Thiru et al., 2003). When carrying out database validation in the human medical field, systematic review papers have suggested that the terms completeness and correctness are the most appropriate for describing data quality (Hogan and Wagner, 1997; Jordan et al., 2004). These terms are also appropriate for validating animal disease databases. Completeness is the proportion of observed or actual disease events that is present in the database. Correctness is the proportion of registered events that is a correct representation of the actual disease event (i.e., conforming to the definition for the diagnostic event registered).

The majority of diagnostic events that are registered in the NDHRS are veterinary attended, although it is possible for the farmer to independently register events. 
Initially, these events are represented by an entry on an individual's cow health card present on farm. Subsequently, these diagnostic events are electronically reported monthly to the central database by the farmer or a herd health advisor. Alternatively, veterinarians may report the same day or within a few days in a new system introduced in June 2008. Medicine use in animals is strictly regulated in Norway, and a veterinarian has to initiate any treatment with a prescription drug. This explains why the majority of the NDHRSregistered events are veterinary attended. The present study was concerned with investigating the data quality in the NDHRS central database as influenced by the steps involved in data transfer from farm to the database. This is the first study specifically looking at this transferring process in Norway for dairy cows. The specific objectives of this study was, thus, to determine agreement between data registered on farm and data in the central database, describing reasons for discrepancies, further presenting data quality as completeness and correctness, and lastly to identify risk factors for data loss based on a multivariable regression analysis. Long term, the results of this study can help to decrease data loss by identifying weaknesses in the system, and as such help prioritizing resources for improvements. Also, finding the strengths of the system highlights what should not be lost in future developments. Issues identified and described may be useful for other countries or regions running or setting up centrally based collections of dairy cow health data. Additionally, this study will contribute to the limited literature on validation studies of animal databases and, lastly, it will give documentation of data quality for researchers using the Norwegian disease data.

\section{MATERIALS AND METHODS}

\section{Dataflow in the NDHRS (Figure 1)}

All Norwegian dairy cows have on farm an individual cardboard cow health card (CHC; Østerås et al., 2007) that must be easily available for veterinarians, other advisory personnel, and inspectors from the food safety authority (Appendix Figure A1). By law, it is the animal owner's responsibility to ensure that any disease and treatment event for any individual is recorded on an approved health card on farm (Ministry of Agriculture and Food, 2012). Herds participating in the NDHRS periodically, normally monthly, report any diagnostic event and any treatment detail to the central cattle database (CCD), managed by TINE SA (the Norwegian Dairy Association, Ås, Norway). This transfer of data from the cardboard CHC to CCD may occur by 1 of 3 different routes (Figure 1): (1) the herd owner reports events using a web-based user interface; (2) the herd owner transfers events from individual $\mathrm{CHC}$ to a paper summarizing herd records and passes this to the TINE herd advisor, who subsequently reports to the CCD; or (3) from June 2008, the attending veterinarian reports directly to the CCD using a smartphone [the veterinarian (VETIN) system; ProfVet AS, 2008]. The date of transfer to the CCD should be added to the $\mathrm{CHC}$ when this is done (Appendix Figure A1). Upon entry of data into the CCD several automated logical data checks are made, regardless of who makes the registrations. These are the presence of the reported cow identification number in the herd, the existence of the reported diagnostic code, and that the date for the event is not ahead of the registration date or that it occurred after the culling of the cow. In addition some disease events such as retained placenta cannot occur before calving, and mastitis cannot occur in males, as examples. The diagnostic event coding system is based on a 3-digit code system (Østerås et al., 2007).

\section{Sampling Procedure}

The unit of study was a diagnostic event on the cardboard $\mathrm{CHC}$ or in the $\mathrm{CCD}$, or both. The primary sampling unit was herd; thus, cluster sampling was performed. The target population, and sample frame, was all herds with a minimum size of 15 cows in 2008 enrolled in the NDHRS: in total, 7,182 herds. Sampling was stratified by county. Random samples of herds from each county were taken, proportional to the number of herds in each county (18 different counties). Determination of the number of diagnostic events needed for the evaluation was based on the formula for sample size of estimating a proportion (Dohoo et al., 2009). After using a confidence of $95 \%$, an absolute error estimate of $\pm 5 \%$, a priori estimated success of data transfer from the $\mathrm{CHC}$ to the CCD of $80 \%$, and a doubling of the initial calculated number of events $(n=246)$, the final calculated number was 492 diagnostic events. The doubling of number of diagnostic events was a practical way of accounting for unknown clustering effect within herd and on cow level, for several different diagnostic events and their transfer to the CCD. The number of herds needed for 492 diagnostic events was based on the expected number of disease events per year for an average herd size and as such amounted to 29 herds. This was increased to 59 herds due to expected feasibility. The sample of 59 herds is hereafter referred to as sample 1, as an additional 25 large herds were also sampled, hereafter referred to as sample 2. Sample 2 was made by taking a simple random sample from all herds with 70 cows or more $(n=92)$. Sample 2 with large herds (large defined with reference to the average 


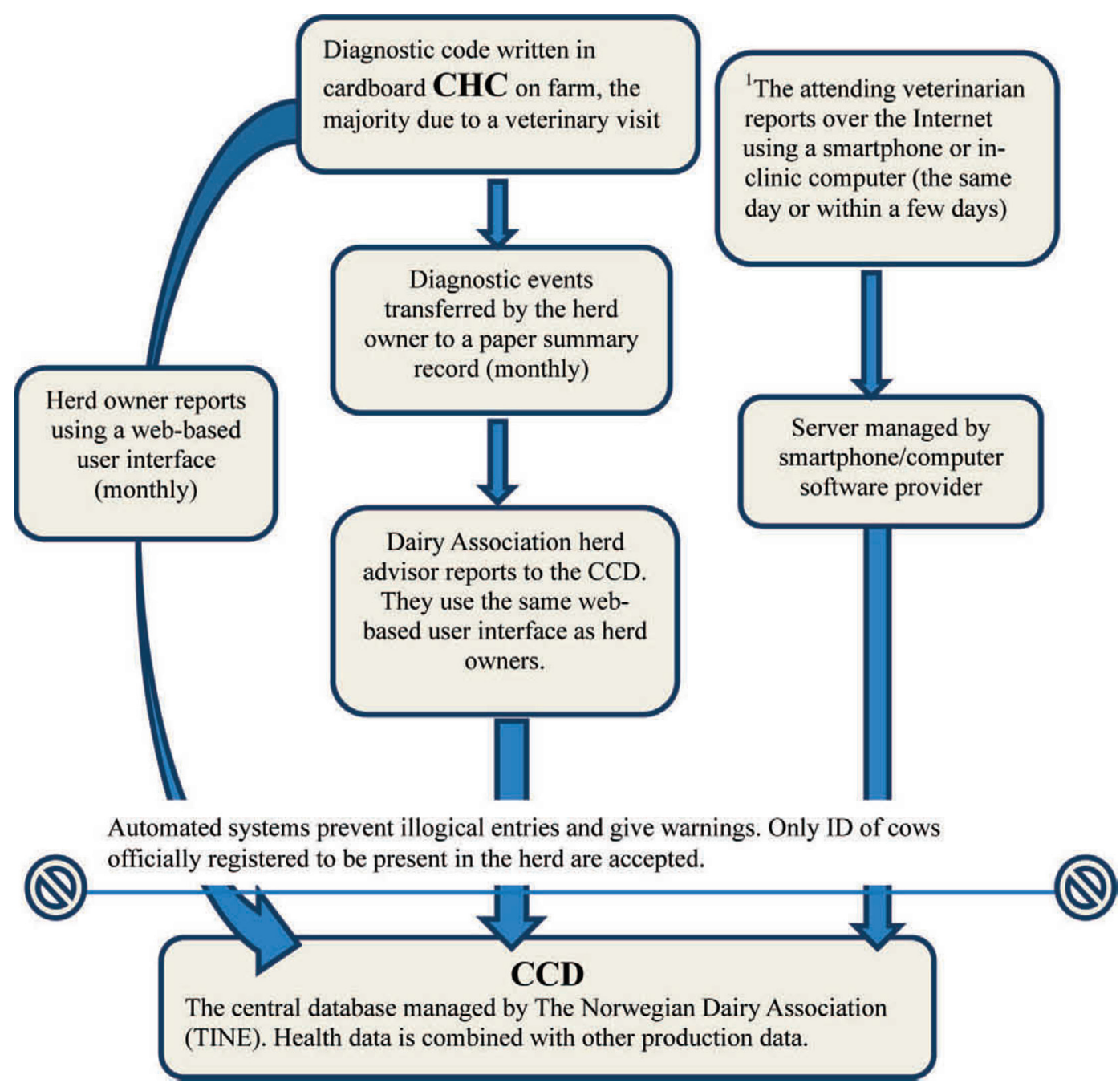

Figure 1. Data flow from farm to the Norwegian national database for dairy cows. ${ }^{1}$ Reporting by the veterinarian was in a start phase from June 2008, and as such was not relevant for this study. CHC $=$ cow health card; CCD = central cattle database; ID $=$ identification. Color version available in the online PDF.

Norwegian herd size of 19.8 cows in 2008) was included to test the hypothesis that data transfer loss could be greater from large herds compared with medium and small herds. All random sampling was automatic using the simple random sample function in JMP 8.0 software (SAS Institute Inc., Cary, NC).

\section{Data Collection}

Extracting CCD Data. Early in June 2009, data for the selected herds were extracted from the CCD. Only diagnostic events from female cattle were included and defined as eligible events if they occurred on or after the date the animal turned 1 yr old. Diagnostic events were here defined as any disease with a 3 -digit disease code that could be entered on the $\mathrm{CHC}$ and in the $\mathrm{CCD}$; these also included preventative treatments [i.e., corresponding disease code +500 (although these were later excluded for analysis)], abnormal findings after reproductive examination, calving problems, and dryoff treatment. For each selected herd, eligible diagnostic event data for 2008 were extracted into checklists, to be used for on-farm comparison with the CHC entries. The checklists included cow identification numbers, the registered date of diagnostic events, registered diagnostic codes, the date the event was reported to the CCD, and 3 check box columns each with a choice of yes or no for the following questions: Does the diagnostic event exist on the CHC? Is the date identical? Is the diagnostic code identical? A free-text column was included for comments if the answer to any of the 3 questions was no. In addition, lists were made of eligible female cattle (hereafter just called cows) existing in each herd in 2008, including their identification number and the 
date they turned 1 yr old. These latter lists were made to ensure that also CHC from cows without any diagnostic events in the CCD were checked for unreported events. Lastly, forms to be filled in with relevant information about any unreported diagnostic events found on $\mathrm{CHC}$ were made. All work with data extraction, management, entry, and later analysis was performed using a combination of Microsoft Excel 2003 (Microsoft Corp., Redmond, WA), JMP 8.0, and SAS 9.2 (SAS Institute Inc.).

On-Farm Comparison of CCD Data with $\boldsymbol{C H} \boldsymbol{C}$. The TINE herd health management advisors (nonveterinarians), hereafter called advisors, performed the checking of $\mathrm{CHC}$ on farms. In total, 68 advisors served the 84 herds. The herd owner and addresses of selected farms were not known to the researchers, only the herd identification number. All advisors servicing the selected herds were in September 2009 sent paper checklists and forms based on CCD data, as detailed above. The advisors collected data from the October 1, 2009, to the January 31, 2010. The herd owner did not have to be directly involved or recall any disease events, as all data collection was based on comparison of paper checklists of extracted CCD data against information filed on farm (i.e., entries in cardboard CHC for 2008).

\section{Data Management}

Returned information on diagnostic events checked in the $\mathrm{CHC}$ and any additional unreported events found on any $\mathrm{CHC}$ were entered and combined with the data table for CCD diagnostic events. All the events where the advisor had noted that all the information was correct (i.e., presence on $\mathrm{CHC}$ and identical diagnostic date and code between the $\mathrm{CCD}$ and the $\mathrm{CHC}$ ) were classified as being in full agreement. All other observations were scrutinized manually and classified into disagreement categories. The disagreement classification resulted in 5 categories: (A) no disagreement, (B) minor disagreement, (C) major disagreement, (D) unreported event found on $\mathrm{CHC}$, and (E) event only present in CCD (Table 1). The last category also included a few events with fictitious dates in the CCD due to a misunderstanding of the registration system. It is only possible to register 1 diagnostic code on any date in the CCD, even if the cow was visited and treated twice for the condition on this date (e.g., a milk fever cow that was seen by a veterinarian both in the morning and afternoon on the same date). To evade the system, the second visit was entered as if it happened the day before or after it actually occurred, giving 2 diagnostic events in CCD when there should only be 1 .

\section{Data Analysis}

Agreement Evaluation. Agreement figures were subsequently calculated for category A to C (i.e., percentage in full agreement, minor disagreement, and major disagreement) according to given formulas (Table 1). This was calculated separately for sample 1 , for sample 2, and combined for sample 1 and 2. Agreement figures solely give information about amount of discrepancy between 2 data sources; neither source is regarded as a reference or an approximate gold standard.

Completeness and Correctness Calculations. Completeness and correctness of the CCD diagnostic events were calculated based on the assumption that the $\mathrm{CHC}$ were the best available representation of the

Table 1. The comparison of individual dairy cow diagnostic events in the cow health card (CHC) and the Norwegian central cattle database (CCD), criteria for agreement evaluation, and formulas used for calculation of agreement, disagreement, completeness, and correctness ${ }^{1}$

\begin{tabular}{ll}
\hline Category & Description $^{2}$ \\
\hline $\mathrm{A}=$ full agreement & $\begin{array}{l}\text { Diagnostic event found in both CHC and CCD for the same cow ID, with identical event } \\
\text { date and diagnostic code } \\
\text { Diagnostic event found in both CHC and CCD for the same cow ID, date discrepancy of up } \\
\text { to } 7 \mathrm{~d} \text { and (or) diagnostic code discrepancy, but both diagnostic codes found in the same } \\
\text { body system group of the code system or logically related }\end{array}$ \\
$\begin{array}{l}\text { Diagnostic event found in both CHC and CCD for the same cow ID, major date discrepancy } \\
\text { of more than } 7 \text { d and (or) major code discrepancy (code discrepancy not accepted as minor } \\
\text { in category B). Included events with either major date or major code discrepancy, both } \\
\text { major date and major code discrepancy, or one major discrepancy in combination with one } \\
\text { minor discrepancy } \\
\text { Representing diagnostic events unreported or unsuccessfully reported from the CHC to the } \\
\text { CCD }\end{array}$ \\
$\begin{array}{l}\text { Events mistakenly reported to the CCD or events reported directly to the CCD without first } \\
\text { being registered on the CHC }\end{array}$ \\
\hline
\end{tabular}

${ }^{1}$ Formulas used: full agreement $=\mathrm{A} /(\mathrm{A}+\mathrm{B}+\mathrm{C}+\mathrm{D}+\mathrm{E})$; minor disagreement $=\mathrm{B} /(\mathrm{A}+\mathrm{B}+\mathrm{C}+\mathrm{D}+\mathrm{E})$; major disagreement $=\mathrm{C} /(\mathrm{A}+$ $\mathrm{B}+\mathrm{C}+\mathrm{D}+\mathrm{E}) ;$ completeness $=(\mathrm{A}+\mathrm{B}) /(\mathrm{A}+\mathrm{B}+\mathrm{C}+\mathrm{D})$; correctness $=(\mathrm{A}+\mathrm{B}) /(\mathrm{A}+\mathrm{B}+\mathrm{C}+\mathrm{E})$.

${ }^{2} \mathrm{ID}=$ identification. 
disease situation on farm; thus, the $\mathrm{CHC}$ was the reference data source. Completeness was then the proportion of registered events on farm that was captured in the CCD, and correctness the proportion of the CCD events that was a correct representation of the $\mathrm{CHC}$ diagnostic events. Numerators and denominators in the calculations were according to formulas given (Table 1). Exact $95 \%$ confidence intervals for a proportion were calculated for completeness and correctness figures (Casella and Berger, 1990). Statistically significant differences between sample 1 and sample 2 were tested using a 2-proportion 2-tailed z-test (Joosse, 2012).

Regression Analysis. Logistic regression analysis was performed, modeling agreement $0 / 1$ as the outcome. Events classified as only being in minor disagreement were included in the agreement group, agreement $=1$. Disagreement, coded agreement $=0$, included all events in major disagreement, events only present on CHC (i.e., unreported events) or events only in the CCD. Explanatory variables were categorical and those explored in the initial analysis were the average herd size for 2008 measured in cow-years, the person having reported the majority of diagnostic events from the farm CHC to the CCD (i.e., farmer or herd advisor as veterinary reporting was only in a start phase in 2008), the geographical region the farm belonged to, the disease code group for the diagnostic code, if the diagnostic code belonged to a preprinted code on the $\mathrm{CHC}$ or not (i.e., to be selected with a tick in a corresponding column or written by hand; Appendix Figure A1), the age group of the cow when the event occurred, the season when the event occurred, and the event in relation to the lactation period; PROC GLIMMIX in SAS 9.2 was used, with the herd identification number as a random effect. Initially, modeling each explanatory variable separately for unconditional analysis and those with a 2-tailed significance value of $P \leq 0.20$ was further explored in a multivariable analysis. A multivariable model using manual forward selection, including explanatory variables in order of significance from unconditional analysis, was then fitted. The 2-tailed significance value for being retained in the final model was $P<0.05$, given by the type 3 test for fixed effects. Significance of all 2-way interaction terms of available explanatory variables was explored. The intraclass correlation (ICC) coefficient was calculated according to formula given by Dohoo et al. (2009): ICC $=\sigma_{\text {herd }}^{2} /\left(\sigma_{\text {herd }}^{2}+\pi^{2} / 3\right)$, where $\sigma_{\text {herd }}^{2}$ is the covariance parameter estimate given in the SAS output. Model goodness of fit was judged by comparing the Akaike information criterion values and checking the Pearson chi-square/degrees of freedom. The latter was for the final model 0.81, indicating a good fit.

\section{RESULTS}

\section{Descriptive Results}

Of the total 84 sampled herds, 79 were visited by advisors. The 5 dropouts were due to stopped farming $(\mathrm{n}=1)$, major rebuilding $(\mathrm{n}=1)$, and unknown $(\mathrm{n}=$ 3). A further 2 herds were withdrawn due to incomplete checking of the CHC. Another 3 herds did not have any diagnostic events registered in the CCD and no unreported events were found on the CHC.

Initially then, 74 herds contributed 2,097 diagnostic events extracted from the CCD or found only on CHC. Of these, 359 events were excluded: 187 preventative treatments, 2 unreported CHC events with missing date and diagnostic code, and $170 \mathrm{CCD}$ events from cows with missing $\mathrm{CHC}$. The reasons for missing $\mathrm{CHC}$ were discarded due to culling of the cow $(44.1 \%)$, damaged $(34.1 \%)$, no reason given $(18.8 \%)$, cow sold $(2.4 \%)$, and not received upon purchase of the cow $(0.6 \%)$.

For the agreement evaluation, there were then 1,738 diagnostic events from 1,104 cows. A total of 914 of these events were from 52 herds in sample 1, and these had an average herd size of 26.8 cows. The remaining 824 events were from 22 herds in sample 2 , and these had an average herd size of 85.9 cows. Of the 1,738 diagnostic events, $207(11.9 \%)$ were only present on CHC (Table 2).

\section{Agreement Evaluation}

Generally, the agreement level between the CCD and the $\mathrm{CHC}$ could be regarded as high (Table 3) and if combining the full agreement and minor disagreement events for the sample 1 herds, was $87.5 \%$. The unreported $\mathrm{CHC}$ events had the greatest effect on lack of agreement. The minor disagreement group $(1.7 \%$ of all events evaluated) included 17 events with a minor date discrepancy, 11 events with a minor diagnostic code discrepancy, and 1 event with both a minor date and a minor diagnostic code discrepancy. The major disagreement group ( $0.9 \%$ of all events evaluated) included 9 events with a major date discrepancy, 4 events with a major diagnostic code discrepancy, and 3 events with both a major date and a major diagnostic code discrepancy.

\section{Completeness and Correctness}

The combined completeness and correctness values were high: 0.87 and 0.97 , respectively (Table 4 ). There were minor differences in completeness and correctness between sample 1 and sample 2 , and no statistically significant differences were found for completeness $(P=$ 
Table 2. Explanations given by advisors for dairy cow diagnostic events being unreported from the cow health card (CHC) to the Norwegian central cattle database (CCD), and their percentage of all the unreported CHC events found during data collection $(\mathrm{n}=207)$

\begin{tabular}{lr}
\hline Item & $\%{ }^{1}$ \\
\hline No explanation & 66.7 \\
Forgotten & 10.6 \\
Expected to be in the CCD as marked as reported on the CHC & 6.8 \\
A second diagnostic code on the same date as another reported diagnostic code & 3.9 \\
Reported after the CCD data were extracted for this study and before on-farm data collection (delayed reporting) & 3.9 \\
On common grazing during the disease event & 2.4 \\
Revisit unreported when it was close in time to the initial visit & 1.4 \\
Miscellaneous & 4.4 \\
\hline
\end{tabular}

${ }^{1}$ Percentage of total unreported events.

$0.22)$ or for correctness $(P=0.21)$. The sample 1 herds obtained an excellent correctness of 0.98 (Table 4).

\section{Regression Analysis}

In the final regression model, 4 explanatory variables were significant and were retained (Table 5). The factors that increased the odds for an event to be in agreement between the $\mathrm{CHC}$ and the $\mathrm{CCD}$ were if the event occurred during the 305-d lactation period; if the event had occurred in a herd with 75 or fewer cows, on average; if the event occurred during the winter, spring, or summer, as one category, rather than autumn; and lastly, if the diagnostic code given to the event was preprinted on the CHC. No interaction terms of statistical significance was found. The random effect of herd was large, as the proportion of model variance at herd level was about $40 \%$ (covariance parameter estimate $=$ 2.171). This means that reporting of data to the CCD was very good from some herds, but poorer from other herds.

\section{DISCUSSION}

\section{Completeness and Correctness}

If data transfer from the CHC to the CCD were perfect, completeness would be $100 \%$. To achieve $100 \%$ completeness is unrealistic, but a data loss of around 12 to $14 \%$ is a concern. The completeness values obtained in this study were slightly higher than that obtained for the Finnish national database at 0.82 (Rintakoski et al., 2012). In a study assessing completeness of the Danish cattle database, estimates from 0.80 to 0.85 were found (Bennedsgaard, 2003), also slightly lower than in this study, but comparable at the higher level. In Sweden, the completeness was found to be lower at 0.75 (Mörk et al., 2010). Differences found in completeness levels may be partly due to study design. The higher completeness in Norway compared with Sweden may be due to a different situation where the Swedish state employed veterinarians and private veterinarians have different reporting systems (Mörk et al., 2009). Mörk et al. (2010) also discovered data loss when data was transferred between 2 central databases.

Differences in completeness level between the Nordic countries for specific diseases has been thoroughly presented elsewhere (Espetvedt et al., 2012; Lind et al., 2012; Wolff et al., 2012). Those studies not only included the data transfer step, but calculated completeness for farmer-observed clinical disease events regardless of veterinary involvement, and a separate completeness for only disease events where the farmer had indicated veterinary involvement. Those studies, thus, also included data loss before a disease event was entered in the CHC. The general pattern showed that severe diseases such as milk fever had for Norway

Table 3. Percentage agreement and disagreement of diagnostic events between cow health cards (CHC) and the Norwegian central cattle database $(\mathrm{CCD})$ for dairy herds in Norway

\begin{tabular}{|c|c|c|c|c|c|c|}
\hline Item & $\begin{array}{l}\text { Total number } \\
\text { of events }\end{array}$ & $\begin{array}{c}\% \text { Full } \\
\text { agreement (no.) }\end{array}$ & $\begin{array}{c}\% \text { Minor } \\
\text { disagreement (no.) }\end{array}$ & $\begin{array}{c}\% \text { Major } \\
\text { disagreement (no.) }\end{array}$ & $\begin{array}{l}\% \text { Only in } \\
\text { CCD }^{2} \text { (no.) }\end{array}$ & $\begin{array}{l}\% \text { Only on } \\
\mathrm{CHC}^{3} \text { (no.) }\end{array}$ \\
\hline Sample 1 & 914 & $85.0(777)$ & $2.5(23)$ & $1.0(9)$ & $0.9(8)$ & $10.6(97)$ \\
\hline Sample 2 & 824 & $83.3(686)$ & $0.7(6)$ & $0.9(7)$ & $1.8(15)$ & $13.3(110)$ \\
\hline
\end{tabular}

${ }^{1}$ All diagnostic events in 2008 were from female cattle of $>1$ yr. Figures are presented separately for random samples of herds with a herd size of at least 15 cows (sample 1: $\mathrm{n}=52$ ) and 70 cows (sample 2: $\mathrm{n}=22$ ) and these 2 samples combined (combined: $\mathrm{n}=74$ ).

${ }^{2}$ Includes events with fictive date in the CCD created close in time to the actual date of the visit, due to a desire to evade the registration rules of only registering a diagnostic code once on any specific date $(\mathrm{n}=7)$.

${ }^{3}$ These are diagnostic events unreported to the CCD, but found on CHC. 
Table 4. Completeness and correctness of diagnostic events in the Norwegian central cattle database $(\mathrm{CCD})^{1}$

\begin{tabular}{lcccc}
\hline Item & Completeness $^{2,3}$ (no.) & $95 \%$ CI & Correctness $^{2,4}$ (no.) & $95 \%$ CI \\
\hline Sample 1 & $0.88(906)$ & $0.86-0.90$ & $0.98(817)$ & $0.97-0.99$ \\
Sample 2 & $0.86(809)$ & $0.83-0.88$ & $0.97(714)$ & $0.95-0.98$ \\
Combined & $0.87(1,715)$ & $0.85-0.89$ & $0.97(1,531)$ & $0.97-0.98$ \\
\hline
\end{tabular}

${ }^{1}$ Diagnostic events in cow health cards (CHC) on farm were used as the data reference source. All diagnostic events in 2008 were from female cattle of $>1$ yr. Figures are presented separately for random samples of dairy herds with a herd size of at least 15 cows (sample $1: \mathrm{n}=52$ ) and 70 cows (sample $2: \mathrm{n}=22$ ), and these 2 samples combined (combined: $\mathrm{n}=74$ ); no. = denominator events in calculation.

${ }^{2}$ Numerator included all events in agreement and minor disagreement between CHC and CCD.

${ }^{3}$ Denominator included all events in agreement, minor disagreement, major disagreement, and those events only present on the CHC (i.e., events unreported to the CCD).

${ }^{4}$ Denominator included all events in agreement, minor disagreement, major disagreement, and events only present in the CCD.

very similar farmer-observed and veterinary involved completeness of around 80\% (Espetvedt et al., 2012), whereas clinical mastitis that ranged from mild to severe varied from 75 to $82 \%$ for farmer-observed and veterinary involved completeness, respectively (Wolff et al., 2012). In the latter publication, incidence rates for mastitis cases were also calculated (23.2 cases per 100 cow-years and 31.3 cases per 100 cow-years in the central database and as observed by farmers, respectively), further giving information about underreporting to the central database. To or knowledge, no other publications exist with estimates of clinical disease incidences on Norwegian dairy farms independent of the CCD data. Correctness was excellent in the CCD, approaching $100 \%$, when using the $\mathrm{CHC}$ as the reference data source. This means that when a diagnostic event was first transferred to the CCD this was done with minimal error. Still, this may be a conservative estimate, as some of the major disagreement events included in the denominator may have been corrections of incorrect entry on the $\mathrm{CHC}$, and actual disease events may have been reported directly to the CCD by the farmer without any entry on the CHC first. To separate events from both of these situations was not possible from the available data.

The calculations of completeness and correctness are dependent on a reference data source that reflects the more true disease status: an approximate gold standard (Hogan and Wagner, 1997). The assumption was made that the $\mathrm{CHC}$ were the best representation of the disease situation on farm. Completeness was then the proportion of the $\mathrm{CHC}$ registered events on farm that was captured in the CCD, and correctness was only estimated in relation to the correct transfer of registered diagnostic code and date of the event.

\section{Agreement Evaluation}

When the agreement evaluation between the 2 data sources was made, neither source was regarded as more reliable than the other. This evaluation identified some reasons for discrepancies and data loss. As expected, the proportion of events existing only on the CHC caused the greatest loss of data in the CCD, reflected also in the reduced completeness discussed above. For about two-thirds of these unreported events, no explanation

Table 5. Multivariable logistic regression, with herd as a random effect, modeling agreement between cow health card (CHC) and the Norwegian central cattle database $(\mathrm{CCD} \text {; agreement }=1)^{1}$

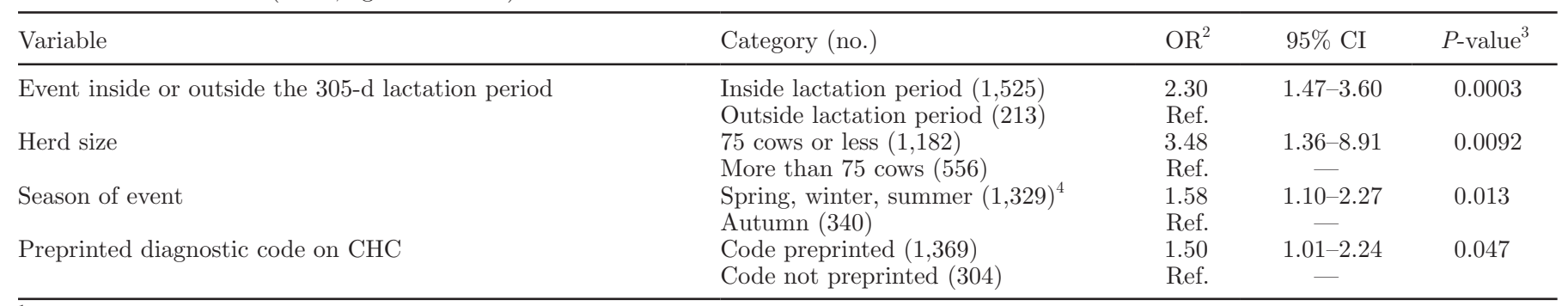

\footnotetext{
${ }^{1}$ All diagnostic events $(n=1,738)$ in 2008 were from female cattle of $>1$ yr, represented by 74 different dairy herds in Norway.

${ }^{2}$ Odds ratio. Ref. $=$ reference.

${ }^{3} P$-values were from type 3 test of fixed effects.

${ }^{4}$ The 3 seasons are grouped together, as separate OR showed no variation when contrasted with autumn.
} 
could be identified, but for the remaining one-third, the dominating reason was that reporting to the CCD was forgotten. It is likely that most unreported events without a given explanation also could be classified as forgotten or be due to that reporting had not been prioritized. Focus on motivation, feedback, and training of herd advisors and farmers involved in transfer of the data may partly solve this problem. Few diagnostic events were in major disagreement: only around $1 \%$ of all the events evaluated. The majority of these were due to date errors (data not shown), and presumably this is due to a typing error either on the $\mathrm{CHC}$ or when reporting to the $\mathrm{CCD}$, or the misinterpretation of illegible handwriting on the CHC. The few events with a major disagreement in diagnostic code are likewise due to either misinterpretation or a typing mistake in either data source. Such manual data entry errors are usually random errors as noted by Arts et al. (2002), and this is the impression for the current study as well.

It should be noted that most $\mathrm{CHC}$ not available for checking had been discarded due to the culling of the cow. By law, the CHC should be retained by the animal owner for a minimum of $10 \mathrm{yr}$ (Ministry of Agriculture and Food, 2012); this finding might, thus, indicate lack of information to the animal owner about storage of the CHC. In Finland, culling of the cow was found to cause data loss due to cow cards being removed before reporting to the central database (Rintakoski et al., 2012). Although the Finnish system is different from the Norwegian, greater lack of transfer of events close to culling of a cow is a possibility, but this could not be investigated from data collected for the current study.

\section{Regression Analysis}

Results of the multivariable regression analysis gives further information about when the Norwegian registration system obtains the best agreement between diagnostic events in the CHC and in the CCD. Diagnostic events that occurred during the 305-d lactation period showed higher agreement compared with those outside the lactation period. Cows in lactation may receive more attention and be perceived as of greater importance, thus given higher priority when it comes to making sure data are transferred to the CCD. It was hypothesized that data transfer loss could be greater from large herds compared with medium and small herds. This was shown to be significant in the regression analysis, although for completeness and correctness estimates, the difference between the sample 1 herds and the sample 2 herds were not statistically significant. Sample 1 also had some large herds, so this may explain the apparent conflict. More data loss from large herds may be due to a higher work load of the herd owner; on the other hand, they should see great benefit from good-quality data, as more systematic herd health work should be a focus. Suspicion exists that some of the larger herds tend to favor their own management software systems on farm, rather than using the information available through NDHRS.

The effect of season seen in the model is more difficult to explain. Slightly more data loss occurred in the autumn compared with the remaining 3 seasons of the year. This may be due to a higher work load in the autumn if many cows have been dried off for summer grazing and then a rush of calvings takes place in the autumn. Also, a busy harvest period is a possible alternative explanation. That a preprinted code on the $\mathrm{CHC}$ is more correctly transferred is logical, as typing mistakes should be less of an issue and these are also the codes most commonly used, reflecting perceived importance and experience in reporting them to the CCD.

\section{Desirable Data Quality}

Arts et al. (2002) discussed that aiming for a registry database that is completely free of errors is unrealistic. Although this was in relation to human health registries, the same applies for animal health databases (i.e., obtaining $100 \%$ agreement, completeness, and correctness in this study could not be expected). Still, looking at only the data transfer process from 1 source (the $\mathrm{CHC}$ ) to another (the CCD), minimal amount of data loss should be expected, obtaining high agreement and completeness. When including minor disagreement events, the agreement and completeness approached $90 \%$ and could be described as high according to other studies (Egenvall et al., 1998; Jordan et al., 2004). Still, the validity of the data for any specific use must be carefully considered. The few studies concerned with data quality in small animal databases have found a discrepancy of $41 \%$ between paper and computer records for diagnoses, procedures, and complications in a veterinary teaching hospital (Pollari et al., 1996), an agreement on diagnosis for health claims of $84 \%$ with a minor disagreement of 6.4\% (Egenvall et al., 1998), and correctness for the diagnosis canine atopic dermatitis of $97.6 \%$, although it could not be determined that all were truly atopic (Nødtvedt et al., 2006). Several more data quality studies have been conducted on human health databases, but Thiru et al. (2003) noted how the lack of standardized methods made it difficult to compare studies and described it as an immature discipline. The variation in completeness found has been large; for example, in a systematic review on electronic patient data in primary care, completeness for diabetes varied between 67 and $100 \%$ (Thiru et al., 2003), and for a systematic review of quality of morbidity coding in computerized general 
practice, records completeness for heart disease diagnoses varied from 47 to $96 \%$ (Jordan et al., 2004). The latter publication concluded that quality of recording varied between morbidities, depending on distinctiveness of diagnosis; for example, higher quality was obtained for diabetes compared with asthma.

In summary and considering also other studies, factors that increase the quality and amount of data in the NDHRS are (1) regulations dictating that only a veterinarian can initiate treatment with prescription medicines, (2) that the CHC acts as a useful on-farm disease and treatment record for the farmer and veterinarian, (3) the diagnostic code system is simple to use with a limited number of codes, (4) reporting to the CCD includes logical data checks and a list of cows present in the herd (from a separate cattle register), and (5) regular feedback through herd reports and easy access to own herd data on the Internet. The likely importance of maintaining these factors should not be ignored, and this study shows that further improvement is possible if achieving prompt reporting of all the $\mathrm{CHC}$ events to the CCD.

\section{Study Challenges and Validity}

The internal validity of this study was dependent on the advisors collecting data checking the $\mathrm{CHC}$ in an accurate and precise manner. To ensure this, attention was paid to easy and self-explanatory forms for filling out while checking the $\mathrm{CHC}$. In addition, the work was carried out by advisors very familiar with the registration system, reimbursed at their standard hour rates. For only a small percentage $(11.2 \%)$ of nonresponse diagnostic events there were no comments about the reason for not checking the $\mathrm{CHC}$. A chance exists that this was due to incomplete checking by the advisors, but due to the relatively low number of events involved this should minimally affect the results. Possibly, it would have been more ideal if data collection had been carried out by only a few technicians specially trained for the task, but this would have been more costly, and with regard to access to farm, would not have benefited from the relationship already established between advisors and farmers. Overall, the impression was that the advisors had performed thorough checking of $\mathrm{CHC}$, and this view was also strengthened by all the unreported events advisors found on CHC. Further, the data from the CCD were extracted in advance of the advisor visits, so it was not possible for advisors to retrospectively make any corrections in the database that could bias the study results. Advisors are, for certain herds, involved in the transfer process to the CCD, but it usually involves the farmer passing on a summarized herd record to the advisor who, in turn, reports to the CCD. This means that the herd advisors do not normally check the CHC entries, and as such were not directly checking their own work during data collection.

The response rate on herd level was high (92\%) and likewise for diagnostic events after preventative treatments were removed (91\%), so if any response bias was present, this should be of minor concern.

No guidelines exist on what cut-off to use for classifying date discrepancies into minor or major when studying data quality; it was here subjectively set at $7 \mathrm{~d}$. For a specific disease and use of the data, this discrepancy may be judged too large or too small. Creating a rule for the minor or major discrepancy of diagnostic code was here straightforward. Consequently, diagnostic code discrepancies were mainly decided in an objective manner. In other studies that have compared registered diagnostic codes to written records, deciding agreement between diagnoses has been a major task and more subjectively carried out (Egenvall et al., 1998; Lawrenson et al., 2000; Penell et al., 2007).

\section{CONCLUSIONS}

This study is the first that has specifically focused on the data-transfer process in Norway for registered diagnostic events in dairy cows on farm to registrations in the central national database. The disease data for dairy cows in the central database is of high quality, and when measured as correctness, can be described as excellent. This makes these data a valuable and valid source for epidemiologic research. Still, the results from this study indicate that improvements can be made in the transfer process, especially by obtaining more complete data. This may be achieved by focusing on motivation, feedback, and systems for prompt data transfer, making sure the usefulness for the farmer is visible, especially for the larger herds. Obtaining better data transfer of diagnostic events outside the lactation period should also be an aim. Some of these issues may be solved by the new system with direct transfer by veterinarians (VETIN), but this could likewise create new problems. Regular validation and monitoring of data in the central database should be carried out to ensure continued data quality and to discover any new problems that may arise.

\section{ACKNOWLEDGMENTS}

Access to data used in this study was provided by the Norwegian Dairy Herd Recording System (NDHRS, Hamar, Norway) and the Norwegian Cattle Health Services (NCHS, Ås, Norway) according to agreement number 004.2007. The study was financially supported by grants from the Nordic Joint Committee for Agri- 
cultural Research (NKJ) via the Research Council of Norway (Oslo, Norway), and by the Norwegian dairy association TINE SA (Ås, Norway). The TINE herd advisors played a crucial role in this study; thanks for doing a thorough job and thanks to Tone Roalkvam for facilitating communication with advisors. Thanks also to other participants in the research group: AnnaMaija Virtala (Department of Veterinary Biosciences, University of Helsinki, Finland); Agneta Egenvall, Ulf Emanuelson, and Cecilia Wolff (Department of Clinical Sciences, Swedish University of Agricultural Sciences, Uppsala); Ann-Kristina Lind and Hans Houe (Department of Large Animal Sciences, Faculty of Life Sciences, University of Copenhagen, Denmark); Ann Lindberg (National Veterinary Institute, Uppsala, Sweden); and Peter Thomsen (Faculty of Agricultural Sciences, Research Centre Foulum, University of Aarhus, Denmark) for valuable comments and input at various stages during the research.

\section{REFERENCES}

Abate, M. L., K. V. Diegert, and H. W. Allen. 1998. A hierarchical approach to improving data quality. Data Qual. J. 33:365-369.

ADHIS (Australian Dairy Herd Improvement Scheme). 2012. Australian Dairy Herd Improvement Scheme. Accessed Nov. 13, 2012. http://www.adhis.com.au/v2/sitev2.nsf/Launch?open.

Andersen, F., O. Østerås, G. H. E. Fjuk, and H. Volden. 2012. Effect of concentrate escalation postpartum on the shape of the lactation curve and health parameters of Norwegian dairy cattle. Livest. Sci. 143:249-258. http://dx.doi.org/10.1016/j.livsci.2011.10.001.

Arts, D. G. T., N. F. de Keizer, and G.-J. Scheffer. 2002. Defining and improving data quality in medical registries: A literature review, case study, and generic framework. J. Am. Med. Inform. Assoc. 9:600-611.

Bartlett, P. C., J. F. Agger, H. Houe, and L. G. Lawson. 2001. Incidence of clinical mastitis in Danish dairy cattle and screening for non-reporting in a passively collected national surveillance system. Prev. Vet. Med. 48:73-83.

Bartlett, P. C., J. B. Kaneene, J. H. Kirk, M. A. Wilke, and J. V. Martenuik. 1986. Development of a computerized dairy herd health data base for epidemiologic research. Prev. Vet. Med. 4:3-14.

Bennedsgaard, T. W. 2003. Reduced use of veterinary drugs in organic dairy herds - Potentials and consequences. PhD Thesis, Royal Veterinary and Agricultural University, Frederiksberg, Denmark.

Casella, G., and R. L. Berger. 1990. Statistical Inference. Pages 444445. Wadsworth \& Brooks/Cole Publishing Co, Pacific Grove, CA.

Dohoo, I., W. Martin, and H. Stryhn. 2009. Veterinary Epidemiology Research. 2nd ed. VER Inc., Charlottetown, PEI, Canada.

Egenvall, A., B. N. Bonnett, P. Olson, and Å. Hedhammar. 1998. Validation of computerized Swedish dog and cat insurance data against veterinary practice records. Prev. Vet. Med. 36:51-65.

EpiCentre. 2005. DairyWIN software. Accessed Nov. 13, 2012. http:// epicentre.massey.ac.nz/Software/DairyWIN/tabid/118/Default.aspx.

Espetvedt, M. N., C. Wolff, S. Rintakoski, A. Lind, and O. Østerås. 2012. Completeness of metabolic disease recordings in Nordic national databases for dairy cows. Prev. Vet. Med. 105:25-37. http://dx.doi.org/10.1016/j.prevetmed.2012.02.011.

Garmo, R. T., A. O. Refsdal, K. Karlberg, E. Ropstad, A. Waldmann, J. F. Beckers, and O. Reksen. 2008. Pregnancy incidence in Norwegian Red cows using nonreturn to estrus, rectal palpation, pregnancy-associated glycoproteins, and progesterone. J. Dairy Sci. 91:3025-3033.

Gulliksen, S. M., K. I. Lie, and O. Østerås. 2009. Calf health monitoring in Norwegian dairy herds. J. Dairy Sci. 92:1660-1669.
Hardeng, F., and V. L. Edge. 2001. Mastitis, ketosis, and milk fever in 31 organic and 93 conventional Norwegian dairy herds. J. Dairy Sci. 84:2673-2679. http://dx.doi.org/10.3168/jds.S00220302(01)74721-2.

Heringstad, B., Y. M. Chang, D. Gianola, and G. Klemetsdal. 2004. Multivariate threshold model analysis of clinical mastitis in multiparous Norwegian dairy cattle. J. Dairy Sci. 87:3038-3046.

Hogan, W. R., and M. M. Wagner. 1997. Accuracy of data in computer-based patient records. J. Am. Med. Inform. Assoc. 4:342-355.

International Committee for Animal Recording. 2012. ICAR home page. Accessed June 2012. http://www.icar.org/index.htm.

Joosse, S. A. 2012. Two-proportion Z-test calculator. Accessed June 3, 2012. http://in-silico.net/statistics/ztest.

Jordan, K., M. Porcheret, and P. Croft. 2004. Quality of morbidity coding in general practice computerized medical records: A systematic review. Fam. Pract. 21:396-412. http://dx.doi.org/10.1093/ fampra/cmh409.

Lawrenson, R., J. C. Todd, G. M. Leydon, T. J. Williams, and R. D. Farmer. 2000. Validation of the diagnosis of venous thromboembolism in general practice database studies. Br. J. Clin. Pharmacol. 49:591-596.

Lind, A., P. T. Thomsen, A. K. Ersbøll, M. N. Espetvedt, C. Wolff, S. Rintakoski, and H. Houe. 2012. Validation of Nordic dairy cattle disease recording databases - Completeness for locomotor disorders. Prev. Vet. Med. 107:204-213. http://dx.doi.org/10.1016/j. prevetmed.2012.06.009.

Ministry of Agriculture and Food. 2012. Norwegian Laws. Lovdata. Forskrift om sporbarhet og merking av storfe mv. Accessed June 21, 2012. http://www.lovdata.no/cgi-wift/ldles?doc=/sf/sf/sf20100709-1131.html.

Mörk, M., A. Lindberg, S. Alenius, I. Vågsholm, and A. Egenvall. 2009. Comparison between dairy cow disease incidence in data registered by farmers and in data from a disease-recording system based on veterinary reporting. Prev. Vet. Med. 88:298-307. http://dx.doi.org/10.1016/j.prevetmed.2008.12.005.

Mörk, M. J., C. Wolff, A. Lindberg, I. Vågsholm, and A. Egenvall. 2010 Validation of a national disease recording system for dairy cattle against veterinary practice records. Prev. Vet. Med. 93:183-192. http://dx.doi.org/10.1016/j.prevetmed.2009.09.016.

Mulder, C. A. T., B. N. Bonnett, S. W. Martin, K. Lissemore, and P. D. Page. 1994. The usefulness of the computerized medical records of one practice for research into pregnancy loss in dairy cows. Prev. Vet. Med. 21:43-63.

National DHIA. 2012. National Dairy Herd Information Association. Accessed Nov. 13, 2012. http://www.dhia.org/default.asp.

NDHRS (Norwegian Dairy Herd Recording System). 2012. The Cow Control Database. Accessed June 18, 2012. http://www.kkvet.no/.

NMR (National Milk Records). 2010. InterHerd dairy herd management software. Accessed June 20, 2012. http://www.nmr.co.uk/ interherd/.

Nødtvedt, A., K. Bergvall, U. Emanuelson, and A. Egenvall. 2006. Canine atopic dermatitis: Validation of recorded diagnosis against practice records in 335 insured Swedish dogs. Acta Vet. Scand. 48:8.

NRS. 1993. The Royal Dutch Cattle Syndicate. Accessed Feb. 7, 2013. http://park.org/Netherlands/pavilions/typical_dutch/cows/ cattle/nrs/\#art.

Olsson, S.-O., P. Baekbo, S. Ö. Hansson, H. Rautala, and O. Østerås. 2001. Disease recording systems and herd health schemes for production diseases. Acta Vet. Scand. Suppl. 94:51-60.

Østerås, O., H. Solbu, A. O. Refsdal, T. Roalkvam, O. Filseth, and A. Minsaas. 2007. Results and evaluation of thirty years of health recordings in the Norwegian dairy cattle population. J. Dairy Sci. 90:4483-4497. http://dx.doi.org/10.3168/jds.2007-0030.

Penell, J. C., B. N. Bonnett, J. Pringle, and A. Egenvall. 2009. Validation of computerized diagnostic information in a clinical database from a national equine clinic network. Acta Vet. Scand. 51:50.

Penell, J. C., A. Egenvall, B. N. Bonnett, and J. Pringle. 2007. Validation of computerized Swedish horse insurance data against veterinary clinical records. Prev. Vet. Med. 82:236-251. http://dx.doi. org/10.1016/j.prevetmed.2007.05.020. 
Pollari, F. L., B. N. Bonnett, D. G. Allen, S. C. Bamsey, and S. W. Martin. 1996. Quality of computerized medical record abstract data at a veterinary teaching hospital. Prev. Vet. Med. 27:141154.

ProfVet AS. 2008. VETIN - et elektronisk samarbeid mellom ProfVet, TINE og Geno (in Norwegian). Accessed Sep. 3, 2012. http:// www.profvet.com/HP/NewsDetail.aspx?ID $=95$.

Rintakoski, S., J. Taponen, O. A. T. Peltoniemi, and A.-M. K. Virtala. 2012. Validation of the Finnish national dairy disease register-Data transfer from cow health cards to the disease register. J. Dairy Sci. 95:4309-4318. http://dx.doi.org/10.3168/jds.20115025.

Salman, M. D., G. R. Frank, D. W. MacVean, J. S. Reif, J. K. Collins, and R. Jones. 1988. Validation of disease diagnoses reported to the National Animal Health Monitoring System from a large Colorado beef feedlot. J. Am. Vet. Med. Assoc. 192:1069-1073.

Sogstad, A. M., O. Østerås, and T. Fjeldaas. 2006. Bovine claw and limb disorders related to reproductive performance and production diseases. J. Dairy Sci. 89:2519-2528. http://dx.doi.org/10.3168/ jds.S0022-0302(06)72327-X.

Sørensen, H. T., S. Sabroe, and J. Olsen. 1996. A framework for evaluation of secondary data sources for epidemiological research. Int. J. Epidemiol. 25:435-442.
Thiru, K., A. Hassey, and F. Sullivan. 2003. Systematic review of scope and quality of electronic patient record data in primary care. BMJ 326:1070-1072.

TINE Rådgiving. 2012. TINE SA. Statistics 2011 (in Norwegian). Accessed May 2012. https://medlem.tine.no/tp/page?id=647.

Wenz, J. R., and S. K. Giebel. 2012. Retrospective evaluation of health event data recording on 50 dairies using Dairy Comp 305. J. Dairy Sci. 95:4699-4706.

Whist, A. C., and O. Østerås. 2007. Associations between somatic cell counts at calving or prior to drying-off and clinical mastitis in the remaining or subsequent lactation. J. Dairy Res. 74:66-73.

Wolff, C., M. Espetvedt, A. K. Lind, S. Rintakoski, A. Egenvall, A. Lindberg, and U. Emanuelson. 2012. Completeness of the disease recording systems for dairy cows in Denmark, Finland, Norway and Sweden with special reference to clinical mastitis. BMC Vet. Res. 8:131 http://dx.doi.org/10.1186/1746-6148-8-131.

Wolff, C., M. Stevenson, U. Emanuelson, A. Egenvall, and A. Lindberg. 2011. Spatial patterns of recorded mastitis incidence and somatic cell counts in Swedish dairy cows: Implications for surveillance. Geospat. Health 6:117-123.

\section{APPENDIX}
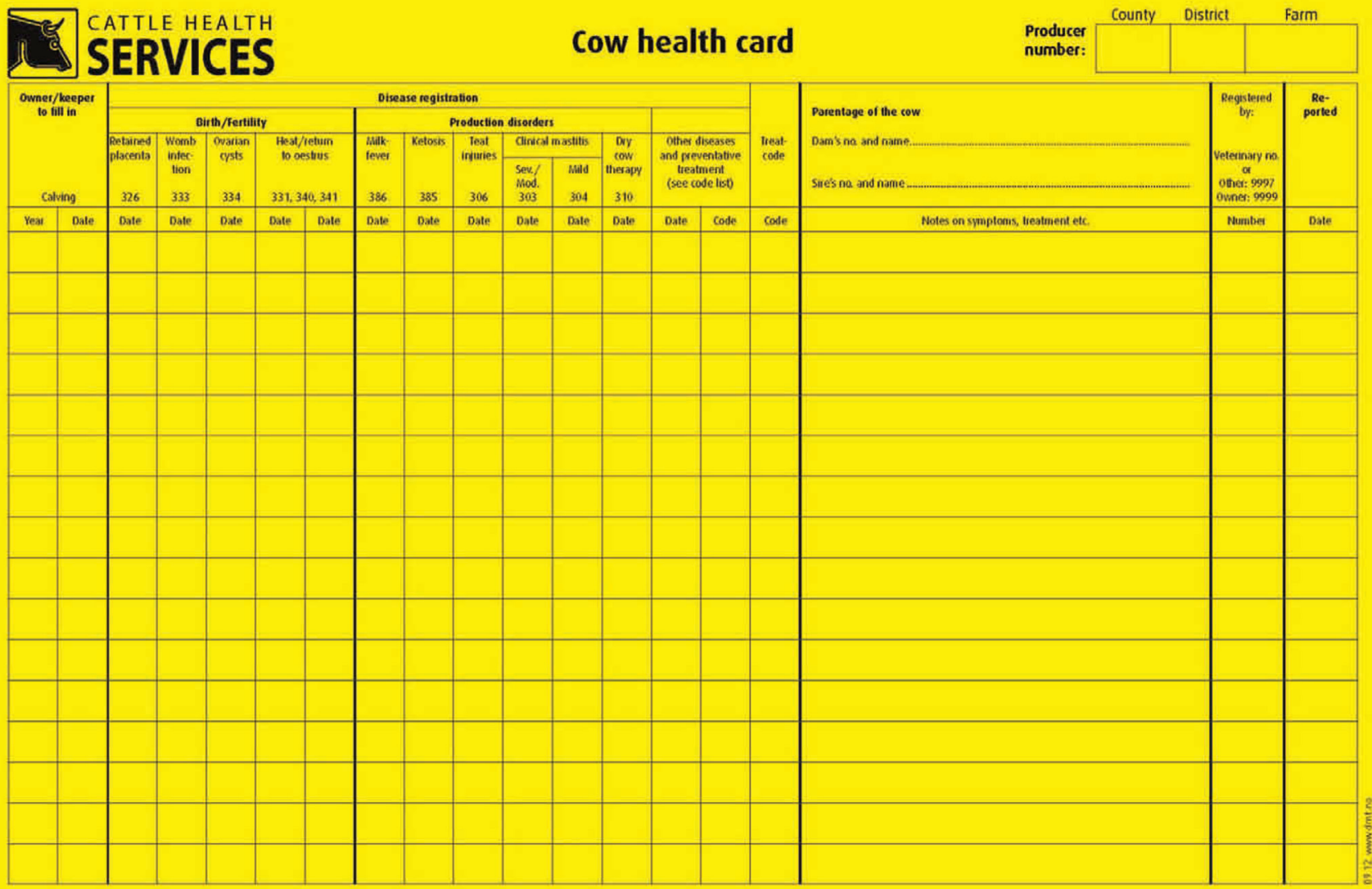

Year of birth and date

Cow's no, and name

Culled/dead date

Reason

Figure A1. Cow health card. Color version available in the online PDF. 